\title{
Destinação de resíduos sólidos e líquidos em propriedades rurais do município de Nhandeara - SP
}

Disposal of solid and liquid waste on rural properties in the municipality of Nhandeara $S P$

Destinacion de resíduos sólidos y liquidos en propiedades rurales del municipio de Nhandeara - SP

Sérgio Luís de Carvalho Professor Doutor, Departamento de Biologia e Zootecnia Faculdade de Engenharia, UNESP, Ilha Solteira - SP, Brasil sergicar@bio.feis.unesp.br

Miguel Spolon Fávero

Eng. Agrônomo, Faculdade de Engenharia, UNESP, Ilha Solteira - SP, Brasil miguelspolonfavero@gmail.com

\section{Orestes Peroni Neto}

Eng. Agrônomo, Faculdade de Engenharia, UNESP, Ilha Solteira - SP, Brasil E:mail: orestes15@hotmail.com 


\section{RESUMO}

A questão ambiental tem sido de grande relevância no mundo atual em face dos impactos provocados à natureza em função das atividades humanas. Entre os impactos gerados ao meio ambiente os resíduos sólidos e líquidos são motivo de grande preocupação pelos problemas que podem ocasionar, tanto no ambiente urbano quanto no ambiente rural. Este trabalho teve como objetivo avaliar alguns parâmetros ambientais em propriedades agropecuárias do Município de Nhandeara - SP. Para tanto, foi aplicado um questionário junto a 45 produtores, contendo 26 questões com diversas respostas, as quais abordam possíveis problemas ambientais nas propriedades e como estes são tratados pelos proprietários. O questionário possibilitou avaliar a questão do descarte de resíduos sólidos e líquidos, de origem doméstica e agrícola como as embalagens de agrotóxicos e o uso de equipamentos de proteção individual (EPI's). A partir das respostas obtidas, constataram-se problemas ambientais com o descarte inadequado do lixo e das embalagens de agrotóxicos, utilização de agrotóxicos sem os equipamentos de proteção e o lançamento de esgoto em sua maioria em fossas negras, ao invés de fossas sépticas. Tais procedimentos podem causar contaminações ao meio ambiente e doenças às pessoas, necessitando-se, portanto, de programas de educação ambiental voltados para a conscientização da comunidade de forma a preservar o meio onde vivem, desenvolvendo suas atividades econômicas de modo sustentável.

\section{PALAVRAS-CHAVE:}

meio ambiente. desenvolvimento sustentável. educação ambiental.

\section{ABSTRACT}

The environmental issue has been of great relevance in the world today in the face of the impacts caused to nature due to human activities. Among the impacts generated on the environment, solid and liquid wastes are a major concern for the problems they can cause, both in the urban environment and in the rural environment. This work had the objective of evaluating some environmental parameters in agricultural properties of the Municipality of Nhandeara - SP. For that, a questionnaire was applied to 45 farmers, containing 26 questions with different answers, which address possible environmental problems in the properties and how these are treated by the owners. The questionnaire made it possible to evaluate the disposal of solid and liquid residues from domestic and agricultural sources such as pesticide containers and the use of personal protective equipment (PPE). From the answers obtained, environmental problems were verified with the inadequate disposal of garbage and agrochemical packaging, the use of agrochemicals without protection equipment and the discharge of sewage, mostly in black cesspits, instead of septic tanks. Such procedures can cause contamination to the environment and diseases to people, therefore, need of environmental education programs aimed at the community awareness in order to preserve the environment where they live, developing their economic activities in a sustainable way.

\section{KEY WORDS}

environmental. sustainable development. environmental education

\section{RESUMEN}

La cuestión ambiental ha sido de gran relevancia en el mundo actual en vista de los impactos provocados a la naturaleza en función de las actividades humanas. Entre los impactos generados al medio ambiente los residuos sólidos y líquidos son motivo de gran preocupación por los problemas que pueden ocasionar, tanto en el ambiente urbano quanto en el ambiente rural. Este trabajo tuvo como objetivo evaluar algunos parámetros ambientales en propiedades agropecuarias del Municipio de Nhandeara - SP. Para ello, se aplicó un cuestionario a 45 productores, conteniendo 26 cuestiones con diversas respuestas, las cuales abordan posibles problemas ambientales en las propiedades y cómo éstos son tratados por los propietarios. El cuestionario posibilitó evaluar la cuestión del descarte de residuos sólidos y líquidos, de origen doméstico y agrícola, como los embalajes de agrotóxicos y el uso de equipamientos de protección individual (EPI's). A partir de las respuestas obtenidas, se constataron problemas ambientales con el descarte inadecuado de la basura y de los envases de agrotóxicos, utilización de agrotóxicos sin los equipos de protección y el lanzamiento de aguas residuales en su mayoría en fosas negras, en lugar de fosas sépticas. Estos procedimientos pueden causar contaminaciones al medio ambiente y enfermedades a las personas, necesitando, por lo tanto, de programas de educación ambiental dirigidos a la concientización de la comunidad para preservar el medio donde viven, desarrollando sus actividades económicas de modo sostenible.

\section{PALABRAS CLAVE}

medio ambiente. desenvolvimiento sustentable. educación ambiental. 


\section{INTRODUÇÃO}

De acordo com DAROLT (2002), lixo rural é composto tanto pelos restos vegetais da cultura e materiais associados à produção agrícola - como adubos químicos, defensivos e suas embalagens, dejetos animais, produtos veterinários, pastilhas e lonas de freios - quanto por sobras semelhantes às produzidas nas cidades - como restos de alimentos, vidros, latas, papéis, papelões, plásticos, pilhas e baterias, lâmpadas etc.

As embalagens de agrotóxicos, sobras de culturas, sucatas de maquinário e dejetos de animais requerem cuidados especiais. Porém, a falta de informação, saneamento e um sistema eficiente de coleta levam muitos agricultores a simplesmente descartar estes materiais ou a adotar práticas perigosas como a queima do lixo. (Mattoso, 2013)

Ao se enterrar o lixo, por exemplo, pode ocorrer a contaminação de lençóis freáticos e do solo, danificando a qualidade de bens fundamentais à produção agrícola. Já a queimada, além de poder gerar incêndios, aumenta a emissão de gases tóxicos na atmosfera. (MARTINI, R.; COSTA, C. D.; BOTEON, M., 2006)

Aproximadamente $70 \%$ dos domicílios rurais queimam, enterram ou lançam os resíduos em terrenos baldios, rios, lagos, igarapés e açudes. Considerando uma média subestimada de $0,1 \mathrm{Kg} /$ pessoa/dia de resíduo sólido doméstico rural em uma população próxima a 30 milhões de habitantes, em um ano tem-se a geração de aproximadamente 1,1 milhão de toneladas de resíduo (PLANO NACIONAL DE RESÍDUOS SÓLIDOS, 2011).

De acordo com dados do Instituto Brasileiro de Geografia e Estatística - IBGE (2006), cerca de $19 \%$ da população brasileira vivia em áreas rurais no ano de 2000 . Apesar do menor número de pessoas residindo no campo, não significa que os danos ambientais provocados pelo lixo sejam menores, já que a coleta de lixo cobre apenas 13,3\% dos domicílios rurais do País (IBGE, 2006), levando muitas vezes a descarte inadequado, o que causa problemas de contaminação do solo, mananciais e alimentos.

Outro grande problema é o descarte incorreto de embalagens vazias de agrotóxicos, as quais são com certa frequência colocadas em locais impróprios, por isso, tornam-se perigosas para o homem, animais e meio ambiente (solo, ar e água). Elas são fontes de contaminação de nascentes, córregos, rios e mananciais de água que abastecem tanto propriedades rurais, quanto as cidades. Além disso, algumas pessoas reutilizam embalagens para armazenar alimentos e ração de animais (INPEV, 2006).

A dificuldade de solução dos impactos ambientais provocados pelo lixo deve-se também à ausência de serviço de coleta e segregação de resíduos de grande parte dos municípios. A importância da coleta seletiva consiste em possibilitar a reciclagem, segundo Sosa (1992), a reciclagem não só possibilita o aumento da vida útil dos materiais, gerando novos negócios empresariais, como também contribui para a proteção ambiental. 


\section{OBJETIVO GERAL}

Avaliar o destino dos resíduos orgânicos e inorgânicos em propriedades rurais localizadas no município de Nhandeara-SP.

\subsection{OBJETIVOS ESPECÍFICOS}

Quantificar as maneiras como os lixos domésticos e agrícolas das propriedades rurais são descartados.

\section{PROCEDIMENTOS METODOLÓGICOS}

\subsection{CARACTERIZAÇÃO DA ÁREA DE ESTUDO}

Nhandeara localiza-se a uma latitude de $20,69^{\circ}$ sul e a uma longitude de $50,03^{\circ}$ oeste, pertence a mesorregião de São José do Rio Preto, conforme pode ser observado na Figura 1. A microrregião de Nhandeara tem 65.337 habitantes (IBGE/2010). A população do município é de 10.725 habitantes (IBGE/2010), distribuídos numa área de $435,771 \mathrm{~km}^{2}$. Seu relevo apresenta altitude de $525 \mathrm{~m}$ e está a $508 \mathrm{~km}$ de distância da capital.

A região possui bioma de cerrado e mata atlântica, tem clima tropical. O verão tem muito mais pluviosidade que o inverno. A classificação do clima é Aw segundo Köppen e Geiger. A temperatura média é $22,3^{\circ} \mathrm{C}, 1.226 \mathrm{~mm}$ é o valor da pluviosidade média anual.

O povoamento na região entre os Rios Tietê e São José dos Dourados iniciou-se por volta de 1890, quando os primeiros habitantes desbravaram as matas para implantação da agricultura e criação de gado.

Figura 1. Localização de Nhandeara no estado de São Paulo

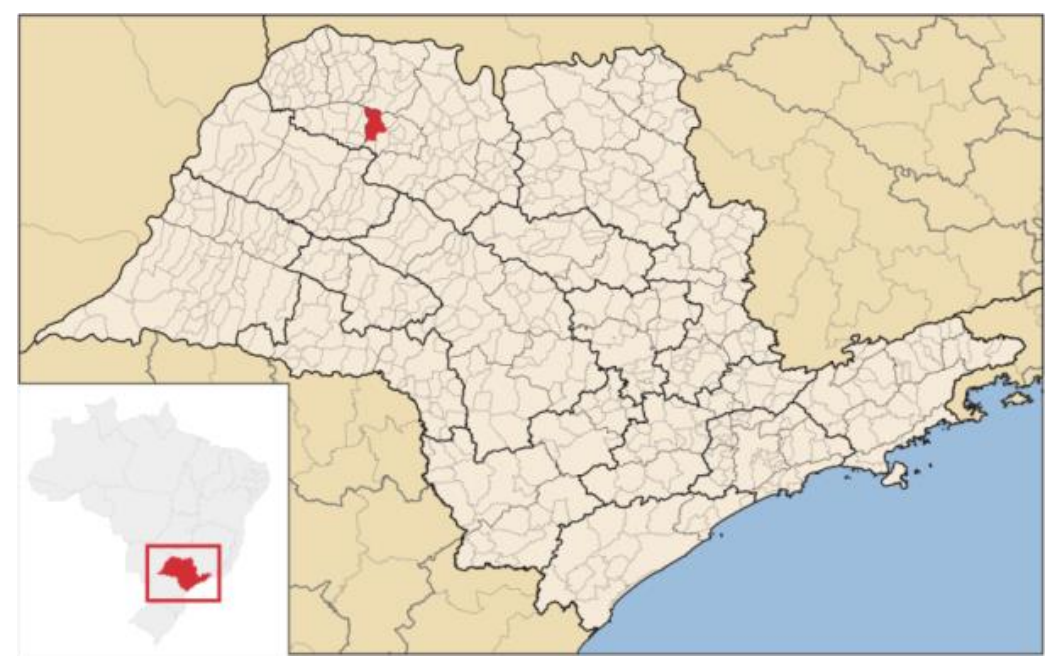




\subsection{METODOLOGIA}

Para avaliar as condições das propriedades do município de Nhandeara, foi formulado um questionário contendo 26 questões, abrangendo diversos itens referentes aos principais problemas causadores de degradação ambiental da região, bem como questões socioeconômicas.

A metodologia utilizada baseia-se em Machado (1982), Colodro et al. (1991) e Martins et al. (2005). Foram escolhidas 45 propriedades, aleatoriamente, e respondidos questionários junto aos responsáveis, abordando temas como composição familiar, fonte de renda, produção vegetal e animal, tecnologia e canais de comercialização, uso de equipamentos de proteção contra defensivos agrícolas e descarte das embalagens, infraestrutura e maquinário da propriedade, lançamento de esgotos, presença e condições de matas ciliares, assoreamento de corpos d'água, destino do lixo, uso e conservação do solo, assistência técnica, em suma, a visão do agricultor em relação à importância da preservação ambiental, além dos problemas e perspectivas vividos.

\section{RESULTADOS E DISCUSSÃO}

Nota-se na Figura 2 os diferentes destinos dados ao lixo gerado nas propriedades, sendo que a maior parte tem o lixo recolhido pela prefeitura, isto é, $36,67 \%$ do papel, $36,66 \%$ do vidro e $36,67 \%$ das latas. Com relação ao lixo orgânico, 33,33\% é recolhido pela prefeitura, 3,33\% é usado como alimento para animais (lavagem) e ainda 16,67\% é usado como esterco, uma forma sustentável de destino do resíduo, a qual diminui a necessidade de adubos químicos. 0 estudo mostrou também que $10 \%$ das propriedades rurais realiza separação para reciclagem do plástico, além de $30 \%$ levar até a cidade e $33,33 \%$ ser recolhido pela prefeitura. No entanto, $20 \%$ delas o enterra e $6,67 \%$ o incinera.

Esses dados mostram a importância do serviço público de coleta de lixo rural, o que evita que o lixo de grande parte das propriedades tenha destino incorreto, como em Dobrada (SP) (Américo et al, 2012) e Santa Rita do Passa Quatro (SP) (Carvalho et al, 2012), em que a incineração é o principal destino do lixo rural, causando grande impacto ambiental. Além disso, observou-se a ausência de compostagem e coleta seletiva de materiais como vidro e papéis, a qual seria importante para o processo de reciclagem. 
Figura 2 - Destinação do lixo doméstico nas propriedades visitadas. Nhandeara-SP, 2014.

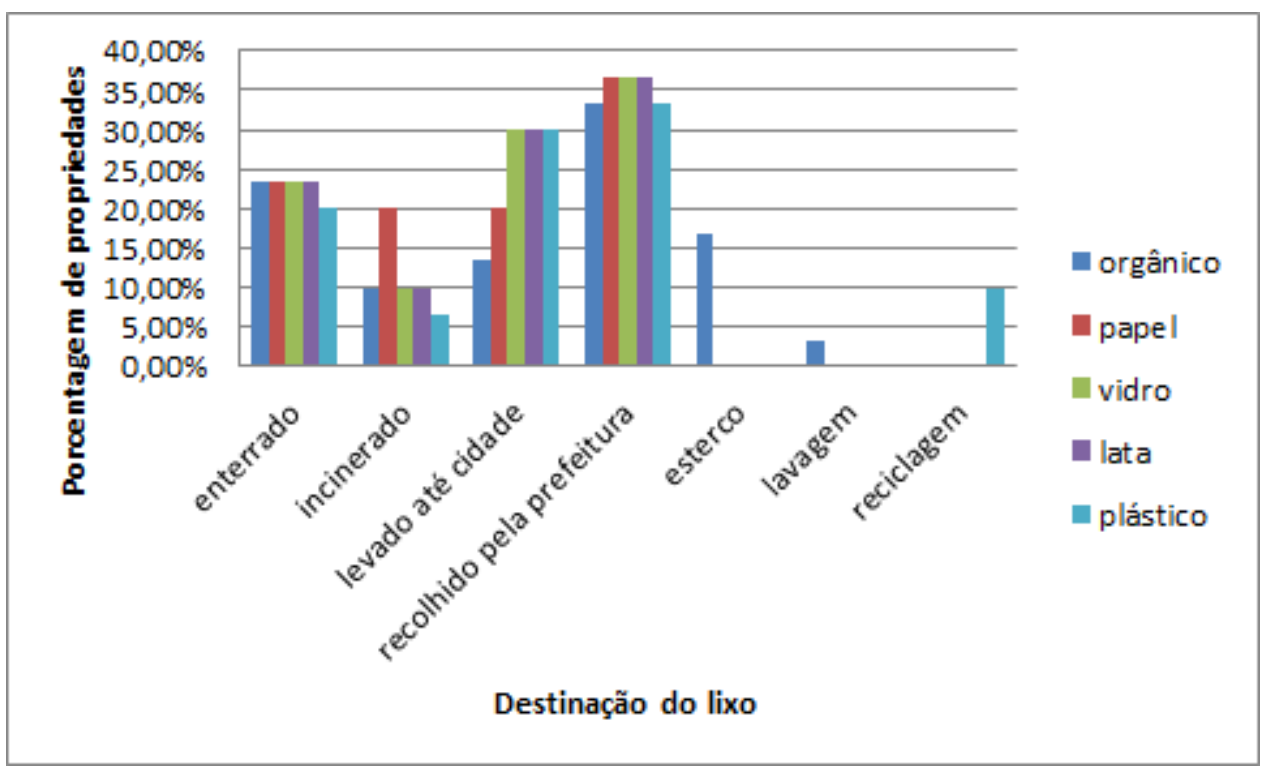

Em relação ao descarte das embalagens de agrotóxicos, observa-se na Figura 3 que $77 \%$ delas são devolvidas, o que contribui para evitar contaminações. Porém, $13,64 \%$ delas são queimadas e $9,09 \%$ armazenadas, provocando danos ambientais.

Tais dados são similares aos encontrados por Sakurai (2015) em Paulo de Faria - SP, onde a maioria dos entrevistados (54\%) alega devolver as embalagens em postos de recebimento. Parte das embalagens é queimada ou devolvida porque a cidade não apresenta tais postos, sendo o mais próximo em Votuporanga-SP, o que dificulta a devolução. 
Figura 3 - Destinação das embalagens de agrotóxicos nas propriedades visitadas. Nhandeara-SP, 2015.

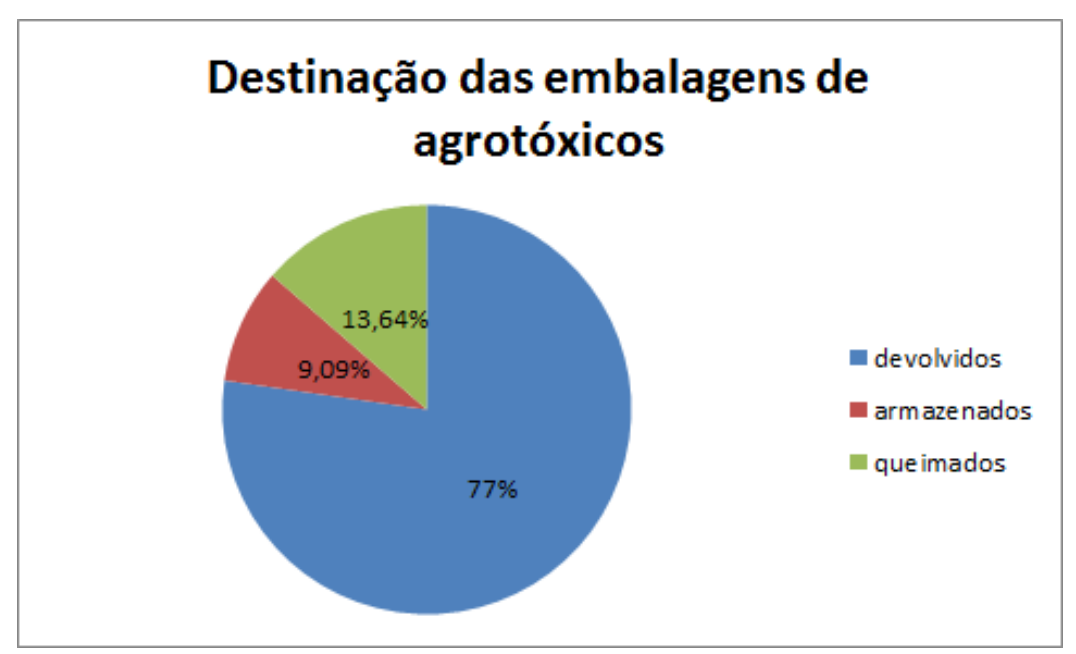

Considerando a relevância e obrigatoriedade do uso de equipamentos de proteção individual (EPI) na aplicação de defensivos agrícolas, analisou-se a utilização destes nas propriedades estudadas. Observa-se na Figura 4 que a maioria dos entrevistados (75\%) alega fazer uso de EPIs, ainda que nem todos utilizem o conjunto completo, no entanto, $25 \%$ do total não utiliza nenhum equipamento, colocando-se em sérios riscos de contaminação. Esses dados são similares aos encontrados por Sakurai (2015) no município de Paulo de Faria - SP, em que 67\% dos produtores utilizam EPIs, enquanto que 33\% não utilizam. Salienta ainda que dos que utilizam, 30\% dos entrevistados disseram fazer uso apenas de luvas, 28\% usam máscaras, 22\% usam roupas de manga comprida e calça jeans*, $11 \%$ usam óculos, $5 \%$ fazem uso de botas e somente 4 \% fazem uso do EPI padrão (utilização de boné, máscara, macacão, avental, luvas e botas). Em estudos anteriores a este, valores similares foram observados por produtores de hortaliças, onde $70,00 \%$ dos produtores não faz uso completo dos EPIs. Isto foi constatado em entrevistas realizadas por Marques (2010) na região de Londrina - PR. 
Figura 4 - Uso de equipamentos de proteção individual nas propriedades agrícolas avaliadas em Nhandeara - SP, 2015.

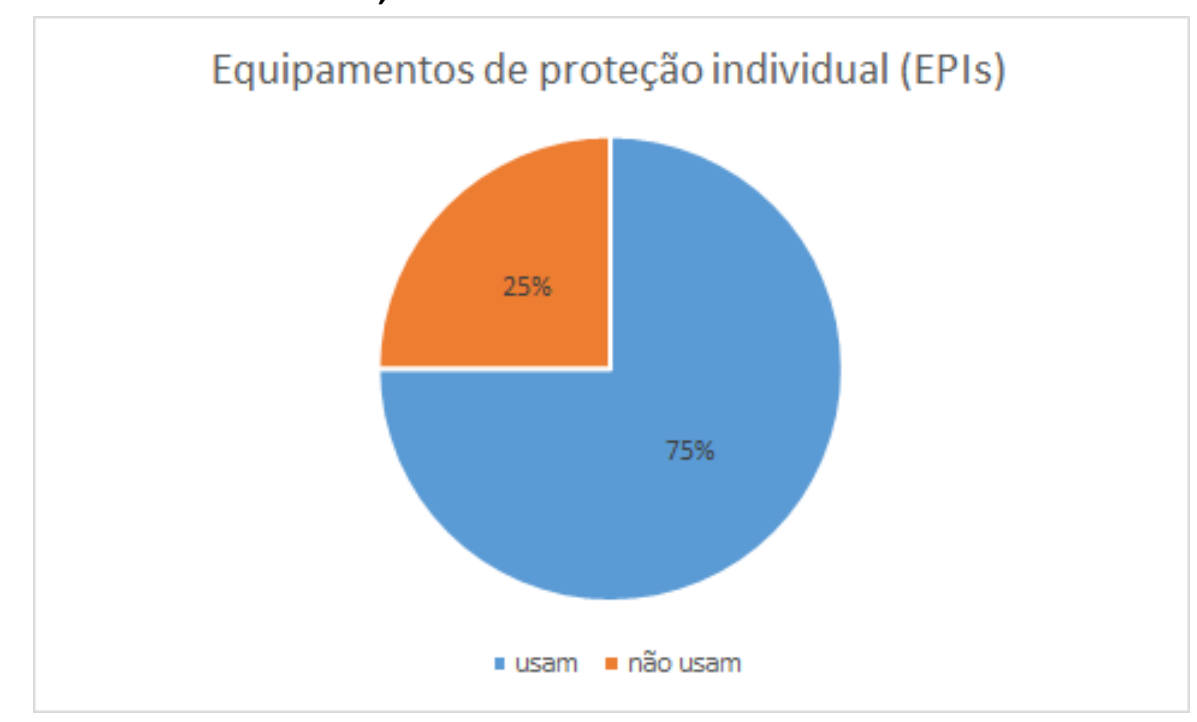

No tocante ao lançamento de esgoto, observa-se na Figura 5 que a maioria das propriedades (80\%) lança seus dejetos em fossas negras, isto é, escavações sem revestimento interno nas paredes e na base, em que não existe nenhum deflúvio e podem proporcionar contaminação do solo e do lençol freático. Entretanto apenas $20 \%$ das propriedades possuem fossa séptica, minimizando riscos de contaminação, bem como de doenças e verminoses. Os dados são semelhantes aos encontrados por Tosti (2014), em que $86,00 \%$ das propriedades analisadas lançam seu esgoto em fossas negras, e o restante $(14,00 \%)$ faz o uso da fossa séptica para lançamento do esgoto produzido no local. Sakurai 2015) por outro lado, relata na região de Paulo de Faria - SP que $44 \%$ das propriedades avaliadas fazem o lançamento em fossas sépticas, , $40 \%$ do total lançam o esgoto em fossas negras e $16 \%$ fazem o lançamento em outros locais, como cursos d'água e diretamente ao solo. 
Figura 5. Tipo de fossa existente nas propriedades avaliadas em Nhandeara - SP, 2015.

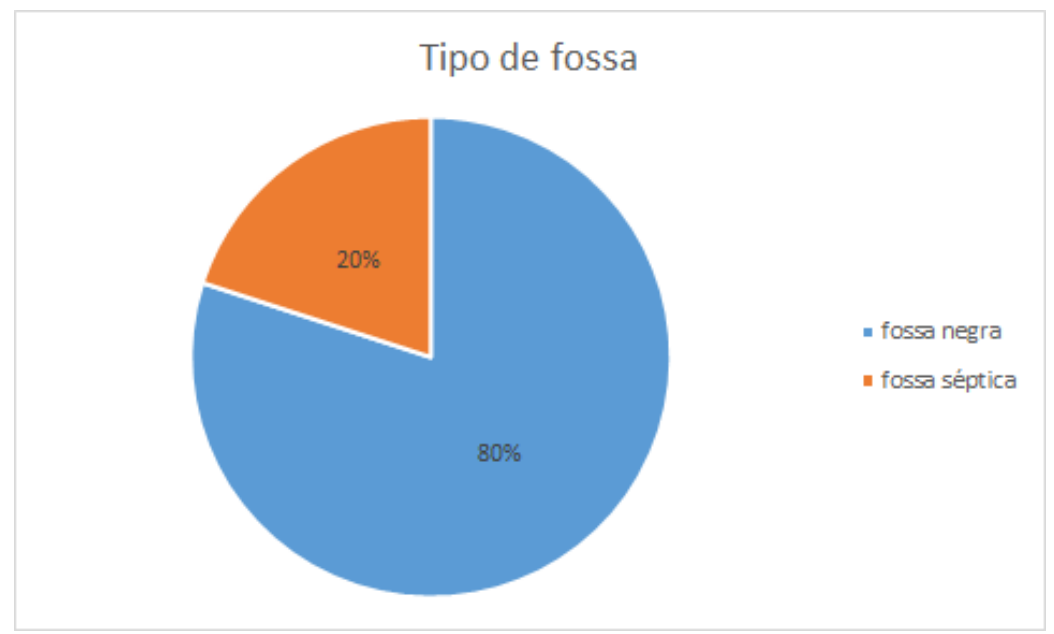

\section{CONCLUSÕES}

Segundo avaliações do destino do lixo gerado nas propriedades rurais, torna-se necessário trabalho de educação ambiental, desde a geração do lixo até o processo de reciclagem. Para tanto, é necessário que a população se conscientize da importância da preservação do meio ambiente, bem como do descarte correto dos resíduos e práticas como reciclagem e compostagem, as quais geram renda para as comunidades locais e diminuem o impacto ambiental.

Cabe ainda ressaltar a importância do serviço público e privado para possibilitar eficiência na coleta do lixo doméstico e agrícola, para diminuir descarte inadequado de resíduos, consequentemente contaminações, poluição do meio ambiente e acúmulo de dejetos.

A maioria das propriedades ainda não dispõe de fossas sépticas, o que se torna um risco ambiental para o solo e o lençol freático.

Constatou-se também um número ainda elevado de pessoas que não utilizam EPI's ou o fazem sem o conjunto completo, estando sujeitos a contaminação por agrotóxicos.

\section{REFERÊNCIAS}

AMÉRICO, J.H.P.; CARVALHO, S.L.; GONZAGA, M.L.; FREITAS LIMA, E.A.C.; ARAÚJO, C.A.M. Condições Ambientais de Propriedades Agrícolas e Percepção Ambiental de Produtores Rurais do Município de Dobrada- São Paulo, Brasil. In: Holos Environment, v. 12, n.2, 2012- p.249.

COLODRO, G., MORAES, M.L., CARVALHO, S.L. Conservação da natureza e Educação em Algumas Cidades do Estado de São Paulo. In: Seminário Regional de Ecologia, 6, 1989, São Carlos, Anais... UFSCAR,1991,529-546

CARVALHO, S. L.; ALMEIDA, F.; FREITAS LIMA, E. A. C. Avaliação das Condições Sócio-Econômico-Ambientais de Algumas Propriedades Agrícolas no Município de Santa Rita do Passa Quatro SP. In: Fórum Ambiental da Alta Paulista, v. 8, n.2, p.348-359, 2012. 
DAROLT, M.R. Lixo Rural: Entraves, Estratégias e Oportunidades. Ponta Grossa: 2002. IAPAR-Instituto Agronômico do Paraná.

IBGE, 2010. Cidades. Disponível em: <http://www.cidades.ibge.gov.br/>. Acesso em: 20 mai. 2015.

IBGE, 2013. Cidades. Disponível

em: $<$ http://www.ibge.com.br/cidadesat/painel/historico.php?lang=_ES\&codmun=353260\&search=sao-

paulo|nhandeara|infograficos:-historico>. Acesso em: 15 jun. 2015.

INSTITUTO NACIONAL DE PROCESSAMENTO DE EMBALAGENS DE AGROTOXICOS VAZIAS - INPEV. 2006. Disponível em:<http://www.inpev.org.br/>. Acesso em: 20 mai 2015.

INSTITUTO NACIONAL DE PROCESSAMENTO DE EMBALAGENS DE AGROTOXICOS VAZIAS - INPEV. Relatório anual 2006, 2006. p $3-121$.

MACHADO, A.B.M. Conservação da natureza e educação. Silvicultura em São Paulo, v.16, n1, p.109-118,1982.

MARQUES, J. G. W. 2010. Etnoecologia, educação ambiental e superação da pobreza em áreas de manguezais. Anais do 1o Encontro Nacional de Educação Ambiental em Áreas de Manguezais, Maragogipe, Brasil, p.29-35.

MARTINI, R.; COSTA, C. D.; BOTEON, M. Gestão do lixo: um estudo sobre as possibilidades de reaproveitamento do lixo das propriedades hortícolas. In: CONGRESSO DA SOBER "Questões Agrárias, Educação no Campo e Desenvolvimento", 44., 2006, Fortaleza. Anais... Fortaleza: Sociedade Brasileira de Economia e Sociologia Rural, 2006. 11p.

MARTINS, M.; CARVALHO, S.L.; FREITAS LIMA, E.A.C.; ARAUJO, C.A.M. Avaliação das condições socioeconômicas de algumas propriedades agrícolas no município de Ilha Solteira/SP. In: Congresso Brasileiro de Administração Rural, 5. 2005, Campinas. Anais. Campinas, 2005. p.1-16.

MATTOSO, G. 0 que fazer com o lixo rural, 25 de jan. 2013. Disponível em:

<http://www.marcosocial.com.br/reportagens/o-que-fazer-com-o-lixo-rural>. Acesso em: 19 mai. 2015.

PLANO NACIONAL DE RESÍDUOS SólIDOS. 2011. Disponível em: http://www.mma.gov.br/estruturas/253/ publicacao/253 publicacao02022012041757.pdf. Acesso em: 06 de 03 de 2015.

SAKURAI, K. Percepção ambiental de produtores rurais e condições sócio-econômico-ambientais de propriedades agropecuárias do município de Paulo de Faria - SP. 2015. 40p. TCC (Graduação) - Curso de Agronomia. UNESP, Ilha Solteira, 2015.

SOSA, M.A. Reciclage: solución empresarial al problema de los desechos solidos. Reciclage, alternativa ambientalista. Caracas, Adan, 1992.

TOSTI, R.S. Percepção ambiental de produtores rurais e condições sócio-econômico-ambientais de algumas propriedades agropecuárias do Município de Santa Fé do Sul - SP e região. 2014. 43p. TCC (Graduação) - Curso de Agronomia, Universidade Estadual Paulista, Ilha Solteira - SP, 2014. 